Medicina Baseada em Euidêneias

\section{HÁ PROFILAXIA PARA A TAQUIARRITMIA ATRIAL PÓS-OPERATÓRIA DE CIRURGIA TORÁCICA?}

A taquiarritmia atrial é complicação muito freqüente no pós-operatório de cirurgia torácica, sendo associada à morbidade significante, aumento do tempo e custo de internação, sobretudo em pacientes idosos.

A profilaxia desses eventos tem sido proposta com o uso de bloqueadores de canal de cálcio, ß-bloqueadores, magnésio, digital e amiodarona. Mas qual o benefício e o dano produzidos por essas drogas na prevenção da taquiarritmia?

Os bloqueadores de canal de cálcio, os ß-bloqueadores, o magnésio e a amiodarona reduzem o risco absoluto (RRA) de taquiarritmia atrial, em cirurgia torácica, em 10,8\% (NNT: 9), 13,7\% (NNT:7) e 16\% (NNT:6), respectivamente. $\bigcirc$ efeito da amiodarona não é significativo, e o digital produz dano, aumentando o risco absoluto (ARA) desse evento em 10,4\% (NNH: 9)!.

Apesar da estimativa de benefício, a ocorrência de eventos adversos foi avaliada apenas com o uso de bloqueadores de cálcio e de ß-bloqueadores, havendo ARA de hipotensão em 6,7\% (NNH: I 5) e 22,9\% (NNH:4), e de bradicardia em 6,2\% (NNH: |6) e 20,4\% (NNH:5), respectivamente.

Apesar das evidências de eficácia, nenhuma dessas drogas deve ser utilizada na prevenção de taquiarritmia pós-operatória de cirurgia torácica, pois:

I. Considerando-se hipotensão e bradicardia como eventos relevantes:

a. Apesar do benefício do magnésio, esses efeitos adversos não foram avaliados adequadamente com o seu uso;

b. Apesar do benefício dos bloqueadores de cálcio e de ß-bloqueadores, o risco de bradicardia é maior, e na hipotensão é importante.

2. Não foram avaliados outros desfechos relevantes como mortalidade e eventos cardiovasculares.

3. Como medida profilática, um número elevado de pacientes será submetido a um risco desnecessário, para um benefício ausente:

a. Bloqueadores de cálcio: de cada nove pacientes tratados, oito não terão benefício (NNT sem benefício);

b. B-bloqueadores: de cada sete pacientes tratados, seis não terão benefício (NNT sem benefício);

c. Magnésio: de cada seis pacientes tratados, cinco não terão benefício (NNT sem benefício).

André DuckWorth Wanderley Marques Bernardo FÁbIO FrazÃo DárIo

Referência

I. Sedrakyan A, Treasure T, Browne J, Krumholz H, Sharpin C, Van der Meulen J. Pharmacologic prophylaxis for postoperative atrial tachyarrhythmia in general thoracic surgery: Evidence from randomized clinical trials. J Thorac Cardiovascular Surg 2005; 129: 997-1005.

\section{Medicina Farmacêutica}

\section{COMO GARANTIR A AUTONOMIA DO SUJElTO DE PESQUISA EM ESTUDOS CLÍNICOS EM PEDIATRIA?}

Em pesquisas clínicas pediátricas, deve haver adicional preocupação referente ao respeito à autonomia do sujeito de pesquisa. $\bigcirc$ Termo de Consentimento Livre e Esclarecido (TCLE), exigido nos estudos envolvendo seres humanos, é em sua essência expressão de autodeterminação (direitos) do ser humano, derivado do respeito ao referencial bioético da autonomia!. Assinar o TCLE representa a anuência do sujeito em participar do estudo.

Crianças são consideradas como vulneráveis em relação a sua inclusão em estudos, uma vez que não estão aptas a consentir sua participação ${ }^{2}$, sendo necessária a autorização por parte dos pais. Crianças estão em processo de desenvolvimento da autonomia e da maturidade ${ }^{3}$ e a competência em consentir a participação em pesquisas depende não somente da idade, mas também do desenvolvimento cognitivo, para que se entenda a responsabilidade, os benefícios e os possíveis danos resultantes da participação no estudo.

Os pais, responsáveis pelos filhos com idade inferior a 18 anos, assinam o TCLE. No entanto, todas as crianças elegíveis para estudos clínicos devem receber informações claras e em linguagem acessível sobre a pesquisa e sobre a possibilidade de participação nesta. É reservado à criança que apresente maturidade suficiente o direito de decidir sobre sua inclusão ou não no estudo, a despeito do consentimento de seus pais ${ }^{3}$. Adolescentes podem, ainda, assinar o TCLE, em conjunto com a assinatura dos pais ${ }^{4}$.

A importância da realização de estudos clínicos em Pediatria é indiscutível, visto que grande parte dos resultados obtidos nos estudos cujos sujeitos de pesquisa são adultos não podem ser simplesmente transpostos para a faixa etária pediátrica. Entretanto, é essencial que os riscos decorrentes do estudo sejam identificados e minimizados, a perspectiva de benefícios diretos seja otimizada, e a participação no estudo resulte em benefícios potenciais maiores ou mais consistentes que os riscos². O TCLE deve conter tais informações de modo claro e em linguagem acessível.

Os profissionais envolvidos na pesquisa clínica em Pediatria exercem fundamental papel no que tange à aplicação do TCLE aos pais. A comunicação deve ser clara, objetiva e simples, com informações verídicas e não tendenciosas. Tanto a criança quanto os pais não devem sentir-se coagidos em participar do estudo e, em especial os pais, devem demonstrar pleno entendimento. Assim, garante-se também o respeito à autonomia do sujeito de pesquisa nas populações pediátricas.

Mariana Bueno

Nanci Valeis

Sonia Mansoldo Daines 